\title{
WORK AND FAMILY: THE PERCEPTION OF BALANCE AMONG FEMALE TEACHERS IN NORTHERN MALAYSIA ${ }^{1}$
}

\author{
AZELIN AZIZ \\ UUM College of Business \\ Universiti Utara Malaysia \\ ARTEMIS CHANG \\ School of Management \\ Queensland University of Technology
}

\begin{abstract}
Women's participation in paid employment has become a common scenario even in non-western developing countries. For example in Malaysia, the trend is growing although the traditional gender role remains strong in Malaysian society. Even though working, women are still expected to assume major responsibilities at home. Thus, as opposed to men, women in this society face the challenge to satisfactorily balance work and family. This study was carried out to explore how Malaysian women perceive the meaning of a balanced work-family life. Sampling women teachers, the interview findings revealed that work-family balance was mainly perceived in terms of an individual's 'ability to fulfill role obligation' appropriately in both the work and family domains. A few participants also viewed balance in the context of role satisfaction and role interference. Overall, the results support the assumption in the literature that perceptions of work-family experience are not universal, rather, the construct of work-family balance is culture-specific.
\end{abstract}

Keywords: Work-family interface, cross-culture, role demands.

\section{Background}

The study of a balanced work-family life has received unprecedented interest from scholars primarily due to the global trend of increased labour force participation by women, coupled with the prevalence of dual-career earners and single-parent families (Aryee, Srinivas \& 
Hwee, 2005; Hansen, 1991). This trend has created a situation where individuals, mainly women, to juggle work and family, hence posing a challenge to successfully manage these multiple roles.

It has been noted that the majority of the work-family studies have been carried out in western societies (Barnett, 1998; Casper, Eby, Bordeaux, Lockwood \& Lambert, 2007; Eby, Casper, Lockwood, Bordeaux \& Brinley, 2005), which is most likely due to the west having formerly experienced a diversified workforce. Nevertheless, women's participation in the labour force has also become a common scenario in non-western developing countries. For these women, being employed poses a new challenge in their lives as the gender role ideologies remain more traditional in these societies (Westman, 2005). That is, men are assumed to be the primary breadwinner, while women are expected to bear the primary role of homemaker and child-carer in the household. Malaysia is one of the countries that represents this situation. In Malaysia, the number of employed women is increasing, and with better education and employment opportunities this increase is likely to continue. At the same time, the traditional gender role is still prevalent across the Malaysian society (Noor, 1999).

The latest statistics (see Table 1) show that more than half of the employed women are married (60.7\%), and $7.3 \%$ are either widowed or divorced (Department of Statistics, Malaysia, 2010). These figures indicate that the majority of women in the labour force are combining work and family roles, hence facing the challenge to juggle these multiple roles successfully. The challenge of managing these combined roles is probably more difficult for widowed or divorced women, as they are also the sole breadwinners in the family.

Table 1

Number and Percentage Distribution of Labour Force by Marital Status, 2010

\begin{tabular}{lrrr}
\hline & Total & Male & Female \\
\hline Total (‘000) (\%) & $11,129.4$ & $7,112.1$ & $4,017.3$ \\
& 100.0 & 100.0 & 100.0 \\
Never married & $3,579.5$ & $2,293.1$ & $1,286.4$ \\
\multirow{2}{*}{ Married } & 32.2 & 32.2 & 32.0 \\
& $7,140.7$ & $4,700.9$ & $2,439.9$ \\
& 64.2 & 66.1 & 60.7 \\
\hline
\end{tabular}




\begin{tabular}{lrrr}
\hline & Total & Male & Female \\
\hline Widowed & 225.0 & 60.7 & 164.3 \\
& 2.0 & 0.9 & 4.1 \\
Divorced/Separated & 184.1 & 57.5 & 126.6 \\
& 1.7 & 0.8 & 3.2 \\
\hline
\end{tabular}

Source. Department of Statistics, Malaysia.

The scarcity of work-family studies in non-western societies has limited our understanding of the work-family interaction in the nonwestern context. This is because the cultural and contextual factors are believed to have their influence on an individual's perceptions and experience in the work and family roles they assumed (Shafiro \& Hammer, 2004). As such, it is plausible to expect that people's perceptions regarding a balanced state of work and family life might somewhat vary across societies.

This paper aims to examine how non-western people perceive the meaning of a balanced work-family life (termed as work-family balance), with specific focus on the Malaysian society. Given the traditional gender role in non-western societies, the act of juggling work and family is particularly pertinent to women employees as opposed to men. Thus, this paper addresses the following research question:

RQ: What does work-family balance mean to Malaysian women?

\section{Defining Work-Family Balance}

Despite gaining academic and applied interest, work-family balance (WFB) has been inconsistently defined (Greenhaus, Collins, \& Shaw, 2003; Gzywacs \& Carlson, 2007). An overview of the literature shows that there was no widely accepted definition of the construct. Most frequently, researchers viewed WFB as a lack of conflict or interference between work and family roles. It has been argued however, that the mere conflict is inadequate to represent WFB as it does not capture the positive aspects of work-family interface that are likely to contribute to a balanced work-family arrangement (Grzywacz, Butler \& Almeida, 2008).

Scholars then began to propose alternative definitions for the WFB construct - among others, focusing on the equality of roles. For example, Marks and MacDermid (1996) used the term 'even-handed' 
to describe balance, emphasizing full engagement across domains, while Kirchmeyer (2000) emphasized the importance of equal distribution of personal resources (i.e. energy, time, commitment) across life roles to achieve balance. Greenhaus et al. (2003) defined WFB as 'the extent to which an individual is equally engaged in and equally satisfied with - his or her work role and family role' (p. 513), in which balance is achieved when input and outcome in each domain are equal. Although all these definitions are true to the balance metaphor, there is little evidence in literature suggesting that people seek 'equality' in their work and family lives (Grzywacz \& Carlson, 2007). Furthermore, it is doubtful if 'equality' across domains is possible.

In another perspective, there were also scholars who conceptualized balance using psychological constructs. For example, Clark (2001) defined WFB as 'satisfaction and good functioning at work and at home with a minimum of role conflict' (p. 349), and Frone (2003) defined WFB as an absence of conflict and a presence of facilitation: 'low levels of inter-role conflict and high levels of inter-role facilitation' represent WFB (p. 145). From this perspective, balance is measured in terms of an individual's judgment as to whether one's expectations about work and family roles are met or not.

As a whole, the various definitions of WFB found in literature do contribute to our understanding of the WFB construct. Although they somewhat vary from each other, these definitions depict a similar connotation of balance, which is successfully managing and juggling work and family roles.

Most of the existing WFB definitions are derived from western perspectives, thus it is doubtful if these definitions would also represent the non-western perspective. This is because work and family systems operate within a wider social, economic and political context (Westman, 2005) and therefore influence the structure of work and family in the setting. For instance, the same occupational type could have different work hours, job descriptions and schedules in different countries. Similarly, the presence of an extended family or a domestic helper living in a household is a more common scenario in non-western than in western countries. Due to these differences, it is reasonable to expect that the demand arising from work and family roles could vary in different settings. What is seen as a demanding aspect of the roles in one setting might not be seen as demanding or an issue of concern in another setting. 
In general, work-family experiences across countries are influenced by the macro- and micro-level factors between the countries. The macro-level factors include differences in aspects such as the economic, social, technological and legislative systems of the country (Joplin, Shaffer, Francesco \& Lau, 2003; Korabik, Lero \& Ayman, 2003; Poelmans, 2003; Sheridan \& Conway, 2001) as well as the micro-level factor, that is the differences in the individual variable, which may include the level of role demands assumed by individuals, coping strategies, personality, values or even the demographic differences between individuals. In comparison, within the cross-cultural field, as opposed to the macro-level differences, researchers have mainly drawn on differences in cultural values as an underlying rationale for the importance and relevance of work-family research outside the western context (e.g. Aryee, Fields \& Luk, 1999; Spector et al., 2004; Yang, Chen, Choi, \& Zou, 2000). The following section discusses the influence of culture in experiencing work and family.

\section{The Cultural Influence}

Forces that lead to various work-family experience across cultures tend to be very similar, however people's responses to these forces are different which tend to be dictated by cultural heritage (Lewis \& Ayudhya, 2006). For example, factors such as long working hours or weekend work might be perceived as harmful to family life in one culture but not in another culture. For that reason, variations were observed in how people of different cultural background experience work and family lives. For instance, in interviews, South Asian women working in the United Kingdom reported difficulty combining work and family life as opposed to their white counterparts - reporting having very little time to participate in domestic chores (Rana, Kagan, Lewis, \& Rout, 1998). Aryee et al. (1999) who tested the generalisability of findings from the US-based model in a sample of 320 Hong Kong employees, revealed that life satisfaction in Hong Kong employees was subjected to work-related factors, while the US employees' life satisfaction was predominantly influenced by family-related factors. Likewise, Yang et al. (2000), who compared US and Chinese employees, reported that US employees perceived greater demands in the family domain than did Chinese employees. Also, family demand had a greater impact on negative work-family experience in US employees, while the Chinese were more influenced by the work demand. These studies serve as evidence that work and family cannot 
be assumed to pose similar effects on employees of different cultural backgrounds. What is seen as stressful in one culture might not be so stressful in another culture.

Due to the need to understand the cultural influence, studies which were predominantly centralized on western societies have then been extended into the cross-cultural perspective. The crosscultural perspective refers to studies that examine both cross-cultural differences and similarities between two or more cultures and ethnic groups, as well as those that provide a non-western perspective from one country (Aycan \& Kanungo, 2001).

The cultural values of individualism-collectivism have often been used to explain societal differences, with the most common reference to Hofstede's (1980) cultural dimension (Westman, 2005). People in western individualist culture are said to view work and family as distinct domains, whereby work denotes personal ambition and achievement. In contrast, non-western collectivist cultures view work and family as interdependent domains that contribute to each other. Work is seen as a means of supporting the family, as opposed to enhancing one's self (Yang et al., 2000).

This shows that people view the function and importance of work and family to themselves somewhat differently in different cultures (Aryee et al., 1999), which would consequently result in differing perceptions on the work-family interrelationship. In line with this, when work and family mean different things to different people, it makes sense to expect that the judgment of balance between these two domains constitutes a somewhat different meaning in different cultures. In view of that, this study aims to fill the gap in literature -that is, to examine the meaning of WFB in people of a non-western society, using Malaysian women as the subjects.

\section{Methodology}

To investigate the issue of concern, the qualitative method was employed. Specifically, the data was collected using an interview technique. Easterby-Smith, Thorpe and Lowe (1991) demonstrated that the interview technique is appropriate for research objectives that aim to understand a construct from the basis of respondents' opinions and beliefs about a particular matter, or to develop an understanding of the respondents' "world". 
The present study focused on women employees as the issue of balancing work and family is of greater concern to women than men in a traditional gender-role society. Women in the teaching profession were sampled due to the common assumption that women enter this profession mainly due to their intent to have a good balance between work and family life. In this regard, these women can be considered to have developed their own views of what a balanced work-family life is like, and thus considered to be an ideal group to sample.

The interviews were conducted with 12 women teachers from the northern region of Malaysia. Only twelve respondents were interviewed because there was no new information or themes observed in the data. Participants were recruited using a purposive sampling technique. This technique allows researchers to select a sample based on the nature of the research objectives, where the researcher will consciously choose elements to be included in the sample on the basis of the appropriateness for the research aims (Green, Tull, \& Albaum, 1999). The present interview targeted married female teachers with children. Hence, the purposive sampling technique was considered practical in acquiring the intended participants. However, it is acknowledged that this kind of sampling will not allow the generalization of findings beyond the sample members (Zikmund, 2003). Semi-structured questions were used to tap their opinions of what a balanced work-family life looks like. Sample questions are "What does a balanced work-family life mean to you?" and "Are you experiencing balance between work and family life? Why?"

Participants were recruited from schools and personal networking. Only four participants were recruited through the schools as it was year-end school holiday at the time the interviews were carried out. Thus, not many teachers were available at schools. Others were recruited via personal networking techniques. Networking involves collecting data from friends and colleagues (Casper, 2000), as well as having these individuals introduce the researcher to other appropriate participants.

The interview transcripts were content-analysed using thematic analysis. Thematic analysis is a widely used qualitative analytic method within and beyond psychology (Braun \& Clarke, 2006). For the present study, the unit of analysis for a code depended on the meaning of the respondents' responses, not on a predetermined decision about coding words, phrases, or sentences. From this analysis, the aim is to gain themes of what is considered to be a "balanced 
work-family life" from the respondents' perspectives. The NVIVO software was used for organizing the data. The coding was done by the researcher and categories were identified. In order to minimize bias, this analysis was also performed by another independent coder who had been trained beforehand. Before coding, the definitions of the categories were provided based on what was developed by the researcher in the initial coding. This was to ensure consistency in the entire coding process. However, the independent coder was allowed to develop additional categories if necessary.

Cohen's kappa $(\mathrm{K})$ was used to calculate the degree of intercoder agreements. Cohen's kappa coefficient $\mathrm{K}$ relates the number of concordant ratings to the number of discordant ratings while taking into account the agreement of ratings that could be expected by chance. Cohen's kappa can yield values between -1 and +1 . A value of +1 indicates absolute agreement among the coders. A value of 0 shows a purely incidental agreement. Values below 0 indicate an agreement worse than chance. According to Everitt (1996), kappa values between .41 and .60 can be regarded as moderate, and values above .60 as satisfactory or solid agreement. Values above .80 are regarded as nearly perfect agreement.

\section{Findings}

Upon coding the interview transcripts, it was noted that not all responses regarding the interpretation of a balanced work-family life were straightforward. Instead, some of the responses overlapped the coding, and were coded into several categories.

In general, all the responses were well categorized into three categories: role obligation, role satisfaction and role interference. "Role obligation" refers to the responses that reflect balance as a situation in which individuals are able to fulfill their obligations in the work and family domains appropriately. Obligations in the home domain mostly referred to performing household chores and child-caring, while in the work domain, completing work duties was referred to. Representative responses for this dimension are:

"I don't really have balance, sometimes work at school does not really get done, work at home is not completed..."

"I consider it as balanced when I can spend time with kids, manage the house, and settle school duties..." 
“...when I can carry out my work quite successfully, and then at home I can take care of my duties, nothing compromised..."

"If I can get home by $2.30 \mathrm{pm}$ and spend the rest of the hours at home, being with my child, that is considered balance..... when I need to stay back, by the time I get home in the late afternoon, nothing much can be done, at times I'm not even able to cook".

The "role satisfaction" dimension categorized responses that reflect participants' feelings of satisfaction with what they are doing or achieving in their work and family roles. Samples of the responses are:
"...is when I am able to pursue my dream [to have my own career], while not neglecting my family..."
“...as long as I am happy, my work goes well...and I get to spend quality time with my kids...quantity [of time] does not matter to me".

The "role interference" dimension coded participants' responses mentioning work aspects that get carried into the family domain and vice versa; be they the work material or the emotion or strain from one domain that crosses over into the other domain. The samples of the responses that were coded under this dimension are:
“...when our work does not interfere with our family life, like not bringing your work problems to your family or your husband, like saying you are tired etc. Then you go home, just concentrate on the family".
"I always try to finish my work at school, if possible [I] try not to bring home. I rarely bring home [school works]. Usually when I am at home, I only focus on the things at home".

All responses from the twelve interviews were successfully coded into one or more of these categories, as summarized in Table 2. The only disagreement initially arising between the two coders related to coding a response into one or more of the three existing categories. This dispute concerned two transcripts. However, following a discussion between the two coders the disagreement was resolved, resulting in complete agreement for all twelve transcripts. The interrater reliability yielded a kappa coefficient of 1.00 for perfect agreement between the two coders (Everitt, 1996). 
IJMS 20 (2), (1-14) (2013)

Table 2

Participants' Conceptualisations of WFB

\begin{tabular}{cccc}
\hline & \multicolumn{3}{c}{ Dimensions } \\
\cline { 2 - 4 } Participant & Role obligation & Role interference & Role satisfaction \\
\hline 1 & $\sqrt{ }$ & & \\
2 & $\sqrt{ }$ & & \\
3 & $\sqrt{ }$ & & \\
4 & $\sqrt{ }$ & $\sqrt{ }$ \\
5 & $\sqrt{ }$ & $\sqrt{ }$ \\
6 & $\sqrt{ }$ & \\
7 & $\sqrt{ }$ & \\
8 & $\sqrt{ }$ & \\
9 & $\sqrt{ }$ & & \\
10 & $\sqrt{ }$ & & \\
11 & $\sqrt{ }$ & & \\
12 & $\sqrt{ }$ & & \\
\hline
\end{tabular}

\section{Conclusion}

The results of this study revealed that Malaysian women teachers predominantly view WFB as "being able to perform or fulfill role obligation in work and family domains" appropriately. In particular, balance is achieved when work duties are fulfilled, and at the same time, household affairs are well taken care of. In this present study, this way of viewing balance was referred to as the "role obligation" perspective. Only a small number of participants viewed WFB from the "role satisfaction" and "role interference" perspectives. Of these three perspectives, "role obligation" seems to be the most significant, as indicated by the high number of participants who mentioned this aspect when describing a balanced work-family life.

Conceptualizing WFB based on satisfaction and interference perspectives is a common approach in work-family literature (e.g. Clark, 2001; Frone, 2003; Greenhaus et al., 2003). Satisfaction is one of the frequently used constructs, while "interference" has long been used as a proxy to represent balance. Therefore, the presence of "satisfaction" and "interference" elements in the conceptualizations of balance among these participants is not unexpected. However, to the best of the researcher's knowledge, "role obligation" has not been used in conceptualizing WFB. Nevertheless, it was found to be a very 
significant construct in the study setting. This is not surprising given that traditional gender roles are still prevalent in Malaysia (Noor, 1999). Even though working in paid employment, women are still primarily responsible for running the household. Thus, women would perceive a good balance when both domains are functioning well. As such, it is believed that this high importance placed on meeting role obligations when managing combined roles also applies to other Malaysian women, given that studies which sample participants of other work categories in Malaysia also persistently talk about meeting the role demands aspect (e.g. Abd. Razak, Che Omar \& Yunus, 2010; Ahmad, 1997).

The presence of the "satisfaction" and "interference" elements in conceptualizing balance among these non-western participants supports the universality of these constructs in work-family experience conceptions. The low level of concern accorded by these participants to "role interference" in the endeavour to achieve a balanced workfamily life is in line with Yang et al.'s (2000) assumption that a collectivist society views work and family as interrelated domains, thus, interference is less likely to be perceived.

In conclusion, these findings concerning the WFB conceptualization have to some extent supported the emerging argument in literature (e.g. Poelmans et al., 2005) that work-family experience is not a universal experience, but is partly culture-specific. Specifically, in the case of Malaysia, WFB was very much seen from the perspective of fulfilling work and family obligations. The findings also indicate that WFB means different things in different contexts (in this case, western versus non-western Malaysian society), suggesting that the context in which work and family operate matters when studying the issues of work-family interface. Not only are structures such as the work process and availability of resources different, but the cultural values as well. Thus, to some degree, western work-family findings may not be applicable to other regions, and empirical investigation is necessary to understand the work-family experience issues across different contextual and cultural settings.

\section{End Notes}

1. The preliminary data of this paper was presented at the $6^{\text {th }}$ International Conference on Gender Studies (SAMA 6), Penang, Malaysia, November 28-29, 2008. 


\section{References}

Abd Razak, A. Z. A., Che Omar, C. M. Z., \& Yunus, J. N. (2010). Family issues and work-family conflict among medical officers in Malaysian public hospitals. International Journal of Business and Social Science, 1(1), 26-36.

Ahmad, A. (1997). Work-family conflict and social support: A study of female secretaries in Malaysia. Pertanika Journal of Social Science and Humanities, 5(2), 93-101.

Aryee, S., Fields, D., \& Luk, V. (1999). A cross-cultural test of a model of the work-family interface. Journal of Management, 25(4), 491-511.

Aryee, S., Fields, D., \& Luk, V. (1999). A cross-cultural test of a model of the work-family interface. Journal of Management, 25(4), 491-511.

Aryee, S., Srinivas, E. S., \& Hwee, H. T. (2005). Rhythms of life: Antecedents and outcomes of work-family balance in employed parents. Journal of Applied Psychology, 90(1), 132-146.

Aycan, Z., \& Kanungo, R. N. (2001). Cross-cultural industrial and organizational psychology: A critical appraisal of the field and future directions. In N. Anderson, D. S. Ones, H. K. Sinangil \& C. Viswesvarn (Eds.), Handbook of industrial, work and organizational psychology (pp. 385-408). London: Sage Publications.

Barnett, R. C. (1998). Toward a review and reconceptualization of the work/family literature. Genetic, Social \& General Psychology Monographs, 124(2), 125-182.

Braun, V., \& Clarke, V. (2006). Using thematic analysis in psychology. Qualitative Research in Psychology, 3, 77-101.

Casper, W. J. (2000). The effects of work-life benefits and perceived organizational support on organizational attractiveness and employment desirability (Unpublished doctoral dissertation). George Mason University, Fairfax, VA.

Casper, W. J., Eby, L. T., Bordeaux, C., Lockwood, A., \& Lambert, D. (2007). A review of research methods in IO/OB work-family research. Journal of Applied Psychology, 92(1), 28-43.

Clark, S. C. (2001). Work cultures and work/family balance. Journal of Vocational Behavior, 58, 348-365.

Department of Statistics, Malaysia. (2010). Key indicator of the labour market Malaysia. Retrieved from http://www.statistics.gov.my

Easterby-Smith, M., Thorpe, R., \& Lowe, A. (1991). Management research: An introduction. London: Sage Publications. 
Eby, L. T., Casper, W. J., Lockwood, A., Bordeaux, C., \& Brinley, A. (2005). Work and family research in IO/OB: Content analysis and review of the literature (1980-2002). Journal of Vocational Behavior, 66, 124-197.

Everitt, B. (1996). Making sense of statistics in psychology: A second-level course. Oxford, UK: Oxford University Press.

Frone, M. F. (2003). Work-family balance. In J.C. Quick \& L.E. Tetrick (Eds.), Handbook of occupational health psychology (pp. 143-162). Washington: APA.

Green, P.E., Tull, D.S., \& Album, G. (1999). Research for marketing decisions. India: Prentice Hall.

Greenhaus, J. H., Collins, K. M., \& Shaw, J. D. (2003). The relation between work-family balance and quality of life. Journal of Vocational Behavior, 63(3), 510-531.

Grzywacz, J. G., \& Carlson, D. S. (2007). Conceptualizing work family balance: Implications for practice and research. Advances in Developing Human Resources, 9, 455-471.

Grzywacz, J. G., Butler, A. B., \& Almeida, D. M. (2008). Work, family, and health: Work-family balance as a protective factor against stresses of daily life. In A. Marcus-Newhall, D. F. Halpern \& S. J. Tan (Eds.), The changing realities of work and family (pp. 194215). Malden, MA: Blackwell Publishing.

Hansen, G. L. (1991). Balancing work and family: A literature and resource review. Family Relations, 40(3), 348-353.

Hofstede, G. (1980). Culture's consequences: International differences in work-related values. Thousand Oaks, CA: Sage Publications.

Joplin, J. R. W., Shaffer, M. A., Francesco, A. M., \& Lau, T. (2003). The macro-environment and work-family conflict: Development of a cross cultural comparative framework. International Journal of Cross-Cultural Management, 3(3), 305-328.

Kirchmeyer, C. (2000). Work-life initiatives: Greed or benevolence regarding workers' time. In C. L. Cooper \& D. M. Rousseau (Eds.), Trends in organizational behavior (pp. 79-93). West Sussex, UK: John Wiley \& Sons.

Korabik, K., Lero, D. S., \& Ayman, R. (2003). A multi-level approach to cross cultural work-family research: A micro and macro perspective. International Journal of Cross-Cultural Management, 3(3), 289-303.

Lewis, S., \& Ayudhya, U. C. N. (2006). Work and family through an international lens. Retrieved from http://wfnetwork.bc.edu

Marks, S. R., \& MacDermid, S. M. (1996). Multiple roles and the self: A theory of role balance. Journal of Marriage and the Family, $58(2), 417$. 
Noor, N. M. (1999). Roles and women's well-being: Some preliminary findings from Malaysia. Academic Research Library, 41(3/4), 123-145.

Poelmans, 1., O'Driscoll, M., \& Beham, B. (2005). An overview of international research on the work-family interface. In S. A. Y. Poelmans (Ed.), Work and family: An international research perspective (pp. 3-46). New Jersey: Lawrence Erlbaum Associates.

Poelmans, S. (2003). The multi-level 'fit' model of work and family. International Journal of Cross-Cultural Management, 3(3), 267-274.

Rana, B. K., Kagan, C., Lewis, S., \& Rout, U. (1998). British South Asian women managers and professionals: Experiences of work and family. Women in Management Review, 13(6), 221-232.

Sheridan, A., \& Conway, L. (2001). Workplace flexibility: Reconciling the needs of employers and employees. Women in Management Review, 16(1), 5-11.

Shafiro, M., \& Hammer, L. (2004). Work and family: A cross-cultural psychological perspective, a sloan work and family encyclopedia entry. Retrieved from http://wfnetwork.bc.edu

Spector, P. E., Cooper, C. L., Poelmans, S., Allen, T. D., O'driscoll, M., Sanchez, J. I., et al. (2004). A cross-national comparative study of work-family stressors, working hours, and well-being: China and Latin America versus the Anglo world. Personnel Psychology, 57(1), 119-142.

Westman, M. (2005). Cross-cultural differences in crossover research. In S. A. Y. Poelmans (Ed.), Work and family: An international research perspective (pp. 241-260). New Jersey: Lawrence Erlbaum Associates.

Yang, N., Chen, C. C., Choi, J., \& Zou, Y. (2000). Sources of workfamily conflict: A Sino-U.S. comparison of the effects of work and family demands. Academy of Management Journal, 43(1), 113-123.

Zikmund, W. G. (2003). Business research methods (7th ed.). Ohio: South-Western. 